11 - ORIGINAL ARTICLE

ISCHEMIA-REPERFUSION

\title{
Alprostadil attenuates inflammatory aspects and leucocytes adhesion on renal ischemia and reperfusion injury in rats $^{1}$
}

\author{
Bruno Leonardo de Freitas Soares ${ }^{\mathrm{I}}$, Maria Andréia Lopes de Freitas ${ }^{\mathrm{II}}$, Edna Frasson de Souza Montero"II, Guilherme Benjamin \\ Brandão Pitta ${ }^{\mathrm{IV}}$, Fausto Miranda Júniorv
}

DOI: http://dx.doi.org/10.1590/S0102-8650201400140011

${ }^{\mathrm{I}} \mathrm{MD}$, Fellow PhD degree, Post-Graduate Program in Interdisciplinary Surgical Science, Department of Surgery, Federal University of São Paulo (UNIFESP), São Paulo-SP, Brazil. Main author. Responsible for conception, design, intellectual and scientific content of the study.

IIPhD, Associate Professor of critical patient, Faculty of Nursing, Federal University do Vale do São Francisco (UNIVASF), Petrofina-PE, Brazil. Acquisition and interpretation of data, manuscript writing.

II'MD, PhD. Associate Professor Department of Surgery, Laboratory of Surgical Physiopathology (LIM-62), Faculty of Medicine, University of São Paulo, São Paulo, Brazil. Critical revision of the study.

${ }^{\mathrm{IV}} \mathrm{MD}$, PhD. Associate Professor of Surgery, Faculty of Medicine. University of Health Sciences of Alagoas, Maceió, Brazil. Acquisition and interpretation of data, critical revision.

${ }^{v} \mathrm{MD}, \mathrm{PhD}$. Associate Professor of Vascular Surgery, Faculty of Medicine, Department of Surgery, UNIFESP, São Paulo-SP, Brazil. Tutor. Responsible for conception and critical revision of the study.

\section{ABSTRACT}

PURPOSE: To evaluate the effects of alprostadil in an experimental model of ischemia and reperfusion injury (IRI) in rat renal tissue. METHODS: Adult male Wistar rats were randomized into three groups Vehicle-treated group(Veh), Alprostadil-treated(Al), and sham(Sh) group. Veh and Al groups had suprarenal aorta occluded for 30 minutes and reperfused for 60 minutes. Saline or $20 \mu \mathrm{g} /$ $\mathrm{kg}$ of Alprostadil was intravenously infused immediately before declamping. Sh group animals underwent similar procedure without aortic occlusion. Left nephrectomy and blood sampling were performed after 60 minutes of reperfusion. Renal ICAM-1 expression and histological analysis were performed to estimate inflammatory response and tissue disarrangement. Serum biochemical markers for IRI were also measured. Kruskal-Wallis test was used to assess differences between the groups.

RESULTS: There was lower expression of ICAM-1 in groups Veh and Sh. On histologically evaluation, inflammation and necrosis in the Veh group was significantly higher (grades III/IV) than $\mathrm{Al}$ group (Veh $>\mathrm{Al}=\mathrm{Sh} ; \mathrm{p}=0.025)$, as well as $\mathrm{CPK}$ levels $(\mathrm{Veh}>\mathrm{Al}=\mathrm{Sh} ; \mathrm{p}=0.03$ ). CONCLUSION: Alprostadil attenuates the immunohistochemical and histological repercussions in the renal tissue of rats submitted to a post-ischemic reperfusion with supra-renal aortic clamping.

Key words: ischemic preconditioning, Kidney, Oxidative stress, Cytokines, ICAM-1, Alprostadil. 


\section{Introduction}

Ischemia and reperfusion injury (IRI) is a syndrome characterized by an initial lack of blood flow to a region or organ, followed by reperfusion. First studies related to this syndrome are from early last century and highlighted deleterious association between extensive muscular lesions and acute renal failure, myoglobinuria, hyperpotassemia and hemodynamic symptoms. With reperfusion, morphofunctional recovering occurs in the majority of cases. Nevertheless, in a significant proportion, an acidotic metabolic syndrome leading to acute tubular necrosis, cell apoptosis leading to multiorgan failure and death occurs. ${ }^{2}$

This is a clinical condition frequently associated with high morbidity and mortality, especially when associated with some conditions such as aging, diabetes and renal impairment. ${ }^{3}$ Renal insult is mostly related to the magnitude and duration of ischemia, leading to edema and tubule obstruction, mainly after reperfusion, and impaired glomerular filtration. ${ }^{4}$

Oxigen free radicals play an important role in the metabolic events involved on ischemic reperfusion insult ${ }^{5-7}$, as well as neutrophil recruitment and tubular adhesion, all of them intimately related in the early inflammatory phase $\mathrm{e}^{8,9}$.

Within the kidney, the amount of oxygen is fairly bigger than necessary, but the external medullary region consumes more than $80 \%$ of it, indeed, overcoming the brain and myocardium. ${ }^{10,11}$ Therefore, the external medullary region is constantly easily suitable to hypoxia, and it is the first region to be affected due to ischemic insult. This vulnerability is aggravated because renal ischemia is not a homogeneous process. Meanwhile, if flow is reduced by $60 \%$ in superficial cortex, in the external medullar region is greater than $80 \%{ }^{12}$.

Intercellular adhesion molecule type 1 (ICAM-1) is an early acute inflammatory marker, intimately related to leukocyte recruitment and adhesion in tubular cells as well as their detachment ${ }^{13-15}$

Several approaches have been proposed as an attempt to preclude IRI, such as hypothermia, ischemic pre- and postconditioning, as well as several drugs concomitantly and posterior to ischemic insult, ${ }^{16,17}$ with studies suggest potential local and distant benefit after flow restoration through leukotactic inhibition, controlled reperfusion, oxygen-free radical removers, prostaglandin analogs or a combination of these. ${ }^{17,18,19}$

Alprostadil is a prostaglandin-analog drug (PGE1). Recent studies have suggested a potential protective role due to blocking of leukocyte chemoattractant factors, as well as weakening leukocyte adhesion to microvascular endothelium, with lesser tissue expression of some inflammatory markers involved in this process, in particular the Intercellular Adhesion Molecule 1 (ICAM-1), possibly leading to a cytoprotective activity also by lowering peripheral vascular resistance ${ }^{20-24}$

The objective of this study was to evaluate the effects of intravenous injection of Alprostadil on an acute model of suprarenal aortic clamping on the renal tissue of rats.

\section{Methods}

All animals were handled according to the ethical principles of laboratory animal care, and this study's protocol was approved by the Research Ethics Committee of the State University of Health Sciences of Alagoas.

\section{Experimental groups and surgical procedure}

Adult male Wistar rats were randomly divided into three groups: Veh Group (Veh), Alprostadil-treated group (Al), and Sham group (Sh). Veh and $\mathrm{Al}$ animals underwent infrarenal aortic occlusion for 30 minutes, following reperfusion for 60 minutes. Saline solution (Veh and Sh) or $20 \mu \mathrm{g} / \mathrm{kg}$ of Alprostadil (Al) was intravenously infused immediately before declamping. SG animals underwent a similar procedure without infrarrenal aortic occlusion. Left nephrectomy and blood sampling were performed in all groups after 60 minutes of reperfusion.

The rats were anesthetized with ketamine hydrochloride $(75 \mathrm{mg} / \mathrm{kg})$ and xylazine $(10 \mathrm{mg} / \mathrm{kg})$ intraperitoneally and $\mathrm{kept}$ spontaneously breathing in room air, followed by tracheostomy. Additional doses were administered, when necessary.

The animals were placed over a constantly heated plate $\left(37^{\circ} \mathrm{C}\right)$ in supine position with hind limbs immobilized. Trichotomy was performed on the operative area with a razor blade followed by antisepsis of the operative area with iodine polyvinylpyrrolidone tincture. Laparotomy was performed approximately $4 \mathrm{~cm}$ long with 11 scalpel blade. Using a surgical microscope (DF Vasconcelos), dissection and isolation of the abdominal aorta (Figure 1A), from $1 \mathrm{~cm}$ proximal to its bifurcation until immediately above the renal arteries (Figure 1B), with placement of a vascular microclamp (BD Insyte $\left.{ }^{\circledR}\right)$ in $\mathrm{Al}$ and Veh group animals. Clamping efficacy was assessed by repair maneuvers with monofilament in the abdominal aorta, pallor or cyanosis and cooling of the hind limbs and absence of arterial pulsations. After 30 minutes of ischemia the clamp was removed and blood flow reestablished aorta. Saline Solution (Veh group) or Alprostadil 20 micrograms/kg (Al group) were injected in previously cannulated left jugular vein, immediately prior to 
declamping. The reperfusion period was 1 hour. In Sh group, the animals underwent all surgical procedures except arterial occlusion and reperfusion. After a total period of 90 minutes, blood samples were collected and excisional biopsy (left nephrectomy) for histological and immunohistochemical study. Euthanasia was performed by a lethal anesthetic dose at the end of procedure.

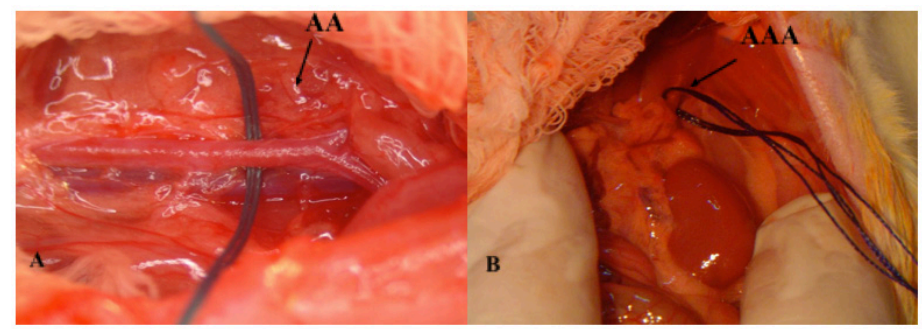

FIGURE 1 - (A) Isolation of abdominal aorta (AA). (B) Isolation of supra-renal abdominal aorta (AAA).

\section{Tissue processing and analysis}

Renal samples were identified, sliced and immersed in $4 \%$ buffered formaldehyde, dehydrated and embedded in paraffin. Following, tissue sections of 4 micra were mounted on slides for staining with hematoxylin and eosin or immunohistochemical staining for ICAM-1. The expression of ICAM-1, as well as structural tissue architecture, was analysed and graded as follows:

Grade 1: Early cellular edema with occasional expression of ICAM-1;.absence of tubular leukocyte adhesion; renal tissue normal architecture preserved (Figure 2A)

Grade 2: Moderate cellular edema with little expression of ICAM-1; incipient tubular leukocyte adhesion; initial change of tubular architecture; no important vacuolization.

Grade 3: Severe cellular edema; strong expression of ICAM-1; moderate leukocyte adhesion; major disarrangement of tissue architecture; moderate tissue vacuolization.

Grade 4: Pronounced cell edema; diffuse expression of ICAM-1 and leukocyte adhesion; diffuse and severe tissue vacuolization; marked disorganization of architecture in nephrotoxicity with loss of cellular and tubular obstruction limits.

Changes in the kidneys were examined histologically covering the degree of inflammation and necrosis as previously published $^{25}$.

Blood levels of lactate dehydrogenase (LDH), Urea and Creatine phosphokinase (CPK) through kinetic method using optimized ultraviolet reading (Targa BT 3000), as previuosly published. ${ }^{26}$ Potassium blood assays were performed with flame spectrophotometer and Calcium levels using colorimetric method with cresolphthalein complex (Abbott VP® Analyzer Biochromatic device). Measurement of serum creatinine by kinetic method in an alkaline medium with picric acid (ABBOTT ${ }^{\circledR}$ device-100R). Arterial blood gas measurements of $\mathrm{pO} 2, \mathrm{pCO} 2, \mathrm{pH}$ and bicarbonate were performed. (Radiometer blood gas 5-ABL, Copenhagen).

\section{Statistical analysis}

The data were analyzed using SPSS software (Statistical Package for Social Sciences, IBM, USA) version 9.0 for Windows. The results among groups were compared by Kruskal-Wallis test and complemented by Mann-Whitney and Bonferroni test, for confirmation of significance. Frequency among groups were analyzed with Quisquare test. The level of significance for this study was $5 \%(\mathrm{p}<0.05)$.

\section{Results}

On immunohistochemical analysis, a higher expression of ICAM-1 as well as tissue architecture disarrangement were found in Veh Group when compared to $\mathrm{Al}$ and $\mathrm{Sh}$ groups. There was less leukocyte tubular adhesion in $\mathrm{Al}$ and Sh groups, with lower expression of ICAM-1 and tissue necrosis when compared to Veh group, as described in Figure 2, with statistically significance for grades II and IV (Veh $<$ Al $\sim \mathrm{Sh})$. Grade I samples were significantly more frequent among Sh group, when compared to Veh and Al.
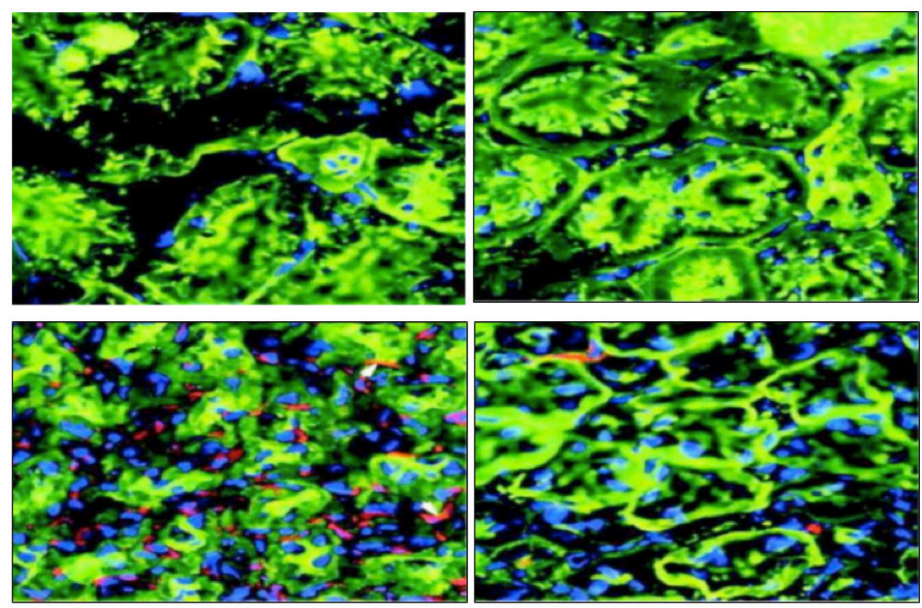

FIGURE 2 - Photomicrograph of analyzing immunohistochemical the expression of intercellular adhesion molecule type 1 (ICAM-1) Grade 1 (A) preserved renal tissue architecture. Grade 2 (B): Initial Change of tubular architecture Grade 3 (C): Disorganization of significant tissue architecture. Grade 4 (D): Intense disorganization of architecture in nephrotoxicity with loss of cellular and tubular obstruction limits.

Regarding to morphological microscopical analysis, higher levels of tissue necrosis and vacuolization were found in the Veh groups, when compared to $\mathrm{Al}$ and $\mathrm{Sh}$, regarding grading scale previously published for optical microscopy analysis, as shown in Figure 3. $(\mathrm{p}=0.025)$ 

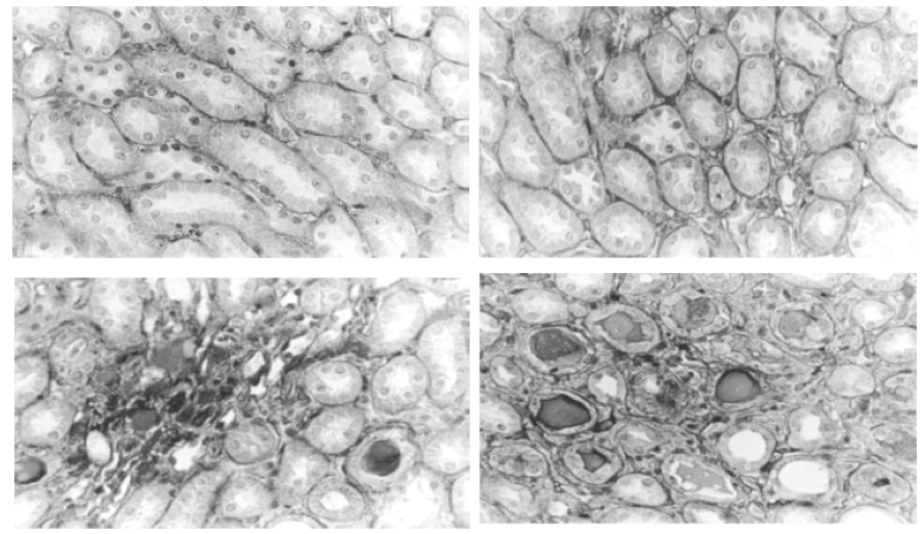

FIGURE 3 - Grade I: Mitosis and necrosis of individual cells. Grade II: necrosis of the proximal convoluted tubules adjacent cells, but these are still viable. Grade III: confined to the distal third of the proximal convoluted tubule necrosis. Grade IV: Necrosis covering all portions of the proximal convoluted tubule with intense interstitial structural breakdowm.

When comparing electrolytes, no statistically significant difference between groups on the levels of Sodium $(p>0.05)$ and Calcium ( $p>0.05$ ) were found. Potassium levels were significantly higher in Veh ( $\mathrm{p}=0.02)$. When comparing LDH levels, they did not differ between groups $(p=0.24)$. Nevertheless, significantly higher levels of CPK were found in Veh animals $(\mathrm{p}=0.03)$. Lactate levels did not show significant difference between groups, as well as urea results. Arterial gasometry, there was no significant differences among groups regarding $\mathrm{pO}_{2}(\mathrm{p}=0.89)$ and $\mathrm{pCO}_{2}(\mathrm{p}=0.12)$ levels. Although $\mathrm{pH}$ was similar between groups, bicarbonate levels were significantly lower in Veh group $(\mathrm{p}=0.012)$ (Figure 4).

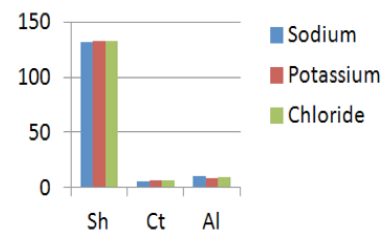

(A)

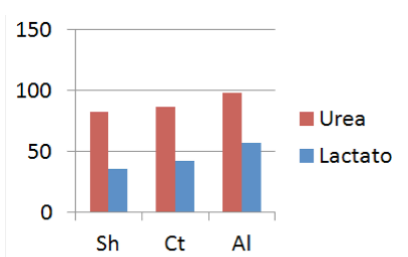

(C)

FIGURE 4 - Systemic serum markers for ischemia and reperfusion. (A) Comparison of electrolyte levels among treatment groups. Kruskal-Wallis test for potassium:Veh $>\mathrm{Al} \sim \mathrm{Sh} \quad(\mathrm{p}=0.02)$; (B) Comparison of LDH (NS*) and CPK levels:Veh $>\mathrm{Al} \sim \mathrm{Sh}(\mathrm{p}=0.03)$; (C) Comparison of Lactate (Kruskal-Wallis: $\mathrm{Veh}>\mathrm{Sh} \sim \mathrm{Al}(\mathrm{p}=0.015)$ ) and Urea (NS*) levels among treatment groups;. (D) pO2 and pCO2, $\mathrm{pH}$ and bicarbonate levels among the groups. Kruskal-Wallis analysis for $\mathrm{pO} 2$ and $\mathrm{pCO} 2$ : Veh $\sim \mathrm{Al} \sim \mathrm{Sh}\left({ }^{*} \mathrm{NS}\right)$. Kruskal-Wallis Test to levels of bicarbonate: $\mathrm{Veh}<\mathrm{Al} \sim \mathrm{Sh}(\mathrm{p}=0.012)$. $* \mathrm{NS}=$ not significant

\section{Discussion}

It is well known fact that morphological changes consistent with ischemic necrosis of renal tubular cells are checked after at least 30 minutes of ischemia and over an hour of reperfusion ${ }^{28-30}$. Experimental models of ischemia and reperfusion are long described and widely found in the literature 16,19-23. Nevertheless, to our best knowledge, this is the first study to analyze the effects of Alprostadil using this experimental model on the renal tissue.

The involvement of free oxygen metabolites as well as its derivatives in the pathogenesis of the metabolic changes which are characteristic of ischemia and reperfusion injury syndrome is well documented and established ${ }^{6}$, as well as the early involvement of activated neutrophils with subsequent diapedesis and leukocyte adhesion in the chain of inflammatory events that culminate in loss of function, tissue disarrangement and necrosis. ${ }^{8}$

Kelly et al..$^{14}$, on a distinct methodological study, have demonstrated a significant improvement when using Alprostadil on late morphological (optic simple microscopy) and biochemical aspects (CPK, Creatinine and Potassium), using longer reperfusion periods ( 4 to 6 hours), evidencing a complete recovery of IRI after a period of 7 days. Indeed, despite of the different experimental model used and timepoint analysis, our results suggest similar benefits regarding these potential histological, immunohistochemical and biochemical features also with shorter clamping time and reperfusion period. We decided to use an acute supra-aortic short clamping time, which could mimic the socalled "optimal" clamping time for most of the clinical vascular procedures involving abdominal aortic clamping. The efficacy of the employed model itself could also be assessed and confirmed, when analyzing the structural tissue disarrangement on group Veh.

Leukocyte signaling, recruitment, diapedesis and tubular attachment are acute initial changes on the physiopathology cascade of events involved in renal IRI. Taking this in consideration, we decided to study the acute biochemical and immunohistochemical inflammatory markers after 60 minutes of reperfusion, in order to assess a potential protective effect of Alprostadil in this specific issue, what proved to be found. ${ }^{13-15}$

Some authors have also studied shorter clamping times with similar reperfusion periods with renal pedicle or single limb artery clamping, suggesting questionable benefit of its use. ${ }^{17-}$ ${ }^{21}$ We believe that these conflicting results are related to short clamping periods, some of what could even controversially work as preconditioning protective factor. Another major difference is the potential to create significant IRI, which is long known to be 
directly related to the ischemic muscular mass involved in the ischemic insult. ${ }^{3,4,6,30}$ Experimental models for IRI using distal arterial clamping were effective with longer clamping periods. Our model proved to induce strong aggressive IRI on the renal tissue, despite of the relative short clamping time and we deem this to the supra-aortic clamping, which lead to direct and indirect mechanism of IRI.

Some authors have demonstrated the role of ICAM-1 in the acute early inflammatory cascade involving the tubular cells in IRI process. ${ }^{13-15,23-26}$ In this study, Alprostadil decreased the expression of this important marker in the $\mathrm{Al}$ group, when compared Veh group, especially regarding the appearance of severe forms of IRI in the renal parenchyma. Despite of different experimental models, our results corroborate with these previous published studies, suggesting that the protective effect of Alprostadil could be implemented through anti-inflammatory routes.

Alprostadil proved to induce statistically significant decrease in the expression of ICAM -1 molecule, especially in the more severe IRI form (grade IV), demonstrating a benefit of its intravenous administration in a model with early infusion immediately before unclamping. These results corroborate the conclusions postulated by Vargas et al. ${ }^{19}$.

Throughout variable analytic methods and experimental models, some authors have evaluated the effects of anti ICAM-1 in protecting organs distant from the ischemic event, some of them using rats, and suggesting that the use of anti-ICAM 1 effectively decreased neutrophil influx, thereby reducing inflammation and tissue damage in muscle and kidney ${ }^{27}$. Our data suggest a potential synergic effect of Alprostadil, as its use lead to a reduction on the amount of neutrophils in the Al group compared to the Veh, and in the comparative immunohistochemical and histological analysis between Sh and Veh groups. We consider these results of major importance, as it suggest that the association of Alprostadil and other anti-ICAM-1 and/or anti-inflammatory agents could have a potential synergistic benefit on renal IRI.

According to this study, it is not possible to point out other physiopathological pathways, even though some of our biochemical findings regarding $\mathrm{CPK}$, potassium and lactate highlight the need for further investigation on free oxygen radical, NO and apoptotic markers. Another interesting possibility for future studies would be the employment of longer perfusion time points, since some of the inflammatory and apoptotic markers demand longer reperfusion endpoint follow up time for their adequate expression.

Vargas et al. suggested that the early and immediate infusion of PGE1 is more beneficial in renal IRI and renal than later administration, what lead us to chose the aforementioned drug infusion immediately before declamping ${ }^{20}$, despite of a distinct experimental model and endpoints. Indeed, our results also point out to a beneficial use of Alprostadil immediately after declamping, leading to a protective effect on the use PGE1 therapy early after the ischemic period. Nevertheless, we did not compare its infusion in different timepoints after declamping, as well as the association of Alprostadil and pre- or postconditioning.

Despite the beneficial effect of Alprostadil in acute renal IRI, additional studies should be conducted to allow a better understanding of the potential benefits even in association with other drugs.

\section{Conclusion}

Alprostadil attenuates morphological alterations and leucocyte adhesion in renal tissue of rats subjected to an ischemia and reperfusion insult.

\section{References}

1. Bywaters EGL, Beall D. Crush injuries with impairment of renal function. Br Med J. 1941 Mar; 1(4185):427-32. PMCID: PMC2161734.

2. Bonventre JV, Yang L, Cellular pathophysiology of ischemic acute kidney injury. J Clin Invest. 2011 Nov; 121(11): 4210-221. doi: 10.1172/JCI45161.

3. Ward M. Factors predictive of acute renal failure in Rhabdomyolysis. Arch Intern Med. 1988 Jul; 148(7):1553-7. doi: 10.1001/ archinte.1998.00380070059015.

4. Myers BD, Moran SM. Hemodynamically mediated acute failure. N Engl J Med. 1986 Jan; 314(2):97-105. doi: 10.1056/ NEJM198601093140207.

5. Silva MG, Castro AA, Ramos EA, Peixoto E, Miranda F Jr, Pitta GB, Costa RF, Juliano Y.. Histological and biochemical serum effects of alpha-tocopherol on ischemia/reperfusion-related injuries induced in the pelvic limb of rats. Acta Cir. Bras. 2005 Set/Out; 20(5): 375-81. doi:10.1590/S0102-86502005000500007.

6. Haimovici H. Muscular, renal and metabolic complications of acute arterial occlusions: myonephropathic-metabolic syndrome. Surgery. 1979 Apr;85(4):461-8. PubMed PMID: 432807.

7. Weinbroum AA, Hochhauser E, Rudick V, Kluger Y. Multiple organ dysfunction after remote circulatory arrest: common pathway of radical oxygen species?. J Trauma. 1999 Oct; 47:691-8. PubMed PMID: 10528603.

8. Weiss T, Eckstein H, Weiss C, Diehm C. Neutrophil function in peripheral arterial occlusive disease: the effects of prostaglandin E1. Vasc Med. 1998 Aug; 3(3):171-5. doi: 10.1177/1358836X9800300301.

9. Babior BM. Phagocytes and oxidative stress. Am J Med. 2000 Jul;109(1):33-44. doi: 10.16/S0002-9343(00)00481-2.

10. Wyss M, Kaddurah-Daouk R. Creatine and creatinine metabolism. Physiol Rev. 2000 Jul; 80(3):1107-213. PubMed PMID:10893433.

11. Gobé G, Zhang XJ, Cuttle L. Bcl-2 genes and growth factor in the pathology of ischemic acute renal failure. Immunology Cell Biol. 1999 Feb; 77:279-86. doi:10.1046/j.1440-1711.1999.00826.x. 
12. Sandwritter WA, Reid UN. Morphology of liver cell necrosis. In: Keppler D, ed. Pathogenesis and mechanisms of liver cell necrosis. Lancaster: MTP Press,1975: 1-14.

13. Rothlein R, Czajkowski M, Kishimoto TK. Intercellular adhesion molecule-1 in the inflammatory response. Chem Immunol. 1991 Jan;50:135-142. PubMed PMID: 1686175.

14. Kelly KJ, Sutton TA, Weathered N, Ray N, Caldwell EJ, Plotkin Z, Dagher PC. Minocycline inhibits apoptosis and inflammation in a rat model of ischemic renal injury. Am J Physiol Renal Physiol. 2004 Oct;287:F760-6. Doi: 10.1152/ajprenal.00050.2004.

15. Kelly CP, O'Keane JC, Orellano J, Schroy PC III, Yang S, LaMont JT, Brady HR. Human colon cancer cells express ICAM-1 in vivo and support LFA-1 dependent lymphocyte adhesion in vitro. Am J Physiol. 1992 Dec; 263:864-70. PubMed PMID: 1362041.

16. McCord JM. Oxigen-derived free radicals in post-ischemic tissue injury. N Engl J Med, 1995 Jan;312:159-63. doi: 10.1056/ NEJM198501173120305.

17. Souza-Moraes MR, David-Filho R, Baptista-Silva JC, Ullian M, Franco MF, Gabriel A Jr., Smith B, Burihan E. Effect of antibodies to intercellular adhesion molecule type 1 on the protection of distant organs during reperfusion syndrome in rats. Braz J Med Biol Res. 2003 May;36:605-12. doi: 10.1590/S0100-879X2003000500007.

18. Beyersdorf F, Matheis G, Hanselmann A et al. Reducing reperfusion injury after acute ischemia in the hindlimb by controlled reperfusion. Thorac Cardiovasc Surg. 1987;35:94-95.

19. Rodhen EL, Teloken C, Rodhen CR. Protector effect of alphatocopherol in renal ischemia reperfusion injury in the rat. J Vasc Bras. 2000;9(3):90-3.

20. Vargas AV, Krishnamurthi V, Masih R, Robinson AV, Schulak JA. Prostaglandin E1 attenuation of ischemic renal reperfusion in the rat. J Am Coll Surg. 1995 Jun;80(6) :713-17. PubMed PMID: 7773485.

21. Gupta PC, Matsushita M, Oda K, Nishikimi N, Sakurai T, Nimura Y. Attenuation of renal ischemia -reperfusion injury in rats by allopurinol and prostaglandin E1. Eur Surg Res. 1998 Feb;30(2):102107. PubMed PMID:9565743.

22. Malinski T, Patton S, Prager M, Polterauer P, Neumayer C, Nanobashvili J, Brovkovych V, Huk I. Prostaglandin E1 reduces ischemia/reperfusion injury by normalizing nitric oxide and superoxide release. Shock 2000 Aug;14(2):234-42. PubMed PMID: 10947172.

23. Chung YK, Chung SH, Hong JP. The effect of prostaglandin E1 versus ischemia-reperfusion injury of musculocutaneous flaps. Ann Plast Surg. 2001 Sep;47(3):316-21. PubMed PMID: 11562038.
24. Darius H, Gierer C, Lindermann S. Prostacyclin inhibits adhesion os polymorphonuclear leukocytes to human vascular endothelial cells due to adhesion molecule independent regulatory mechanisms. Basic Res Cardiol. 2003 jan; 98(1):8-15. doi:10.1007/S00395-0030383-1.

25. Jablonsky FC. Histological aspects of renal ischemia: A morphologic Study. Am J Renal Physiol 1983;81:10-16.

26. Gutmann I \& Wahlefeld A W - Methods of enzymatic analysis. New York: Academic Press, 1974;3:1464.

27. Souza-Moraes MR, David Filho R, Baptista-Silva JCC, Ullian M, Franco MF, Gabriel Jr A, Smith B, Burihan E. Effect of antibodies to intercellular adhesion molecule type 1 on the protection of distant organs during reperfusion syndrome in rats. Braz J Med Biol Research 2003 May;36:605-12. doi: 101590/S0100-879X2003000500007.

28. Ushigone H, Samo H, Okamoto M. The role of tissue factor in renal ischemia reperfusion injury of the rat. J Surg Research. 2002 Feb;102(2):102-109. PubMed PMID:11796005.

29. Saikumar P, Venkatachalam MA. Role of apoptosis in hypoxic/ ischemic damage in the kidney. Semin Nephrol 2003 Nov;23(6):511521. doi: 10.1053/So270-9295(3)00130-X.

30. Parajasingam R, Weight SC, Bell PRF. Prevention of renal impairment following aortic cross-clamping by manipulation of the endogenous renal nitric oxide response. Eur J Vasc Endovasc Surg 2000 Apr;19:396-369. doi: 10.1053/ejvs.1999.1030.

\section{Correspondence:}

Bruno Leonardo de Freitas Soares

Paul Hayse Straße, 64

04347 Leipzig - Germany

Phone: 49034126515202

Cel: 49015739531207

bruno.soares@uni-leipzig.de; bruno.soares@univasf.edu.br; bruno.freitas.univasf@gmail.com

${ }^{1}$ Research performed at Laboratory of Faculty of Medicine, University of Sao Paulo, Brazil. Part of Master degree thesis, Postgraduate Program in Interdisciplinary Surgical Science, Paulista School of Medicine, Federal University of Sao Paulo (UNIFESP), Brazil. 